\title{
Offline and online automatic number comparison
}

Filip Van Opstal • Agnes Moors •

Wim Fias • Tom Verguts

Published online: 2 June 2007

(C) Springer-Verlag 2007

\section{Erratum to: Psychol Res}

\section{DOI 10.1007/s00426-007-0108-4}

It has been drawn to our attention that Fig. 1 is incorrect.

The correct figure is printed below.

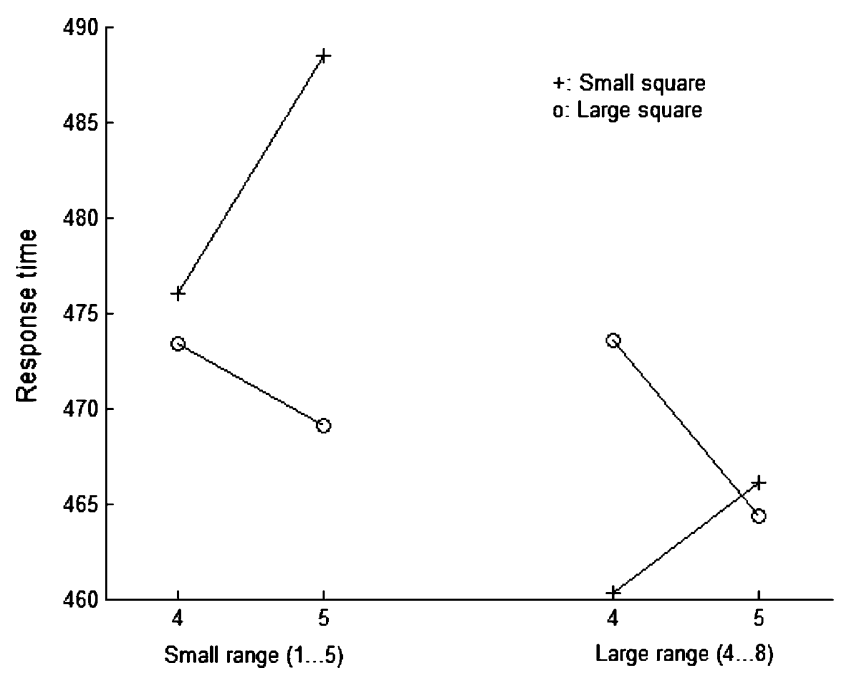

Fig. 1 Data of experiment: mean reaction times on numbers 4 and 5 in the small range (left panel) and in the large range (right panel)

The online version of the original article can be found under doi:10.1007/s00426-007-0108-4.

F. Van Opstal $(\bowtie) \cdot$ W. Fias · T. Verguts

Department of Experimental Psychology, Ghent University,

H. Dunantlaan 2, 9000 Ghent, Belgium

e-mail: Filip.VanOpstal@Ugent.be

\section{A. Moors}

Department of Experimental Clinical and Health Psychology,

Ghent University, Ghent, Belgium 